\title{
IPSILATERAL SUPRACONDYLAR HUMERUS FRACTURE WITH DISTAL END RADIUS FRACTURE - A REVIEW OF 10 CASES
}

\author{
Ayush Kumar Singh', Ujwal Ramteke ${ }^{2}$, Hitesh Mangukiya ${ }^{3}$ \\ ${ }_{1}^{1}$ Senior Registrar, Department of Orthopaedics, Grant Medical College \& Sir J. J. Group of Hospitals, Mumbai. \\ 2Junior Resident, Department of Orthopaedics, Grant Medical College \& Sir J. J. Group of Hospitals, Mumbai. \\ 3Junior Resident, Department of Orthopaedics, Grant Medical College \& Sir J. J. Group of Hospitals, Mumbai.
}

\begin{abstract}
BACKGROUND

Supracondylar humerus fracture with forearm fractures are rare with reported incidence ranging from $3 \%$ to $13 \% .1,2,3,4$ We have treated ten patients with ipsilateral supracondylar humerus fracture with distal radius fracture. One had a Gustilo-Anderson Grade 2 open supracondylar humerus fracture. All displaced fractures were treated with K-wire fixation by closed method except the open fracture which warranted wound debridement and subsequent open reduction. A follow-up of at least 6 months is available for all our patients. All fractures showed signs of union by 6 weeks when K-wires were removed. At 6 months, 9 patients had excellent outcome while one patient with recovering radial nerve palsy had fair outcome. No cases of mal-union, non-union, loss of reduction were seen in the post-operative period. Pin tract site infection was seen in one patient with open fracture which resolved after Kwire removal and antibiotic coverage. This study recommends a screening $\mathrm{X}$-ray of forearm and wrist in patients with supracondylar humerus fractures to rule out any associated forearm/wrist injury. We also recommend closed reduction and K-wire fixation of the displaced supracondylar humerus as well as distal radius fractures. Any nerve palsy if present should be conservatively managed and should be observed for at least 6 weeks before considering surgical exploration.
\end{abstract}

\section{KEYWORDS}

Supracondylar Humerus, Distal Radius.

HOW TO CITE THIS ARTICLE: Singh AK, Ramteke U, Mangukiya H. Ipsilateral supracondylar humerus fracture with distal end radius fracture - A review of 10 cases. J. Evolution Med. Dent. Sci. 2016;5(102):7499-7502, DOI: 10.14260/jemds/2016/1697

\section{BACKGROUND}

Supracondylar humerus fracture and distal radius fracture are common as an isolated fracture but combined supracondylar fracture with distal radius fracture is not a common injury. Both have a similar mechanism of injury, most commonly involving hyperextension injury of upper limb. One article hypothesised that children who sustain a supracondylar fracture have a greater range of elbow hyperextension than those with a fracture of the distal radius. ${ }^{5}$ Hyperextension injury involves hyperextension at wrist and elbow leading to fractures at scaphoid and other carpal bones, radius, ulna, elbow and humerus especially distal humerus. There have been few articles mentioning ipsilateral supracondylar and forearm fracture. The incidence varies from 2 to $13 \%$ as cited in various articles.1,2,3,4 One article has reported 9 cases of isolated distal radius fracture out of 31 cases with ipsilateral supracondylar humerus and forearm fracture studied retrospectively over a period of 5 years. ${ }^{1}$ Other article reported 4 distal radius fractures out of $8(11.1 \%)$ patients with ipsilateral forearm with supracondylar humerus fracture. ${ }^{2}$ Another article reported 22 patients with ipsilateral supracondylar and forearm fracture with 6 patients having radius fracture. ${ }^{3}$ Apart from above-mentioned data, few sporadic cases are reported having the above-mentioned type of injury.6,4,7 Most of the cases reported have been treated with

Financial or Other, Competing Interest: None.

Submission 21-10-2016, Peer Review 11-12-2016,

Acceptance 17-12-2016, Published 22-12-2016.

Corresponding Author:

Dr. Ayush Kumar Singh

\#43, Tota Ka Tal, Lohamandi

Agra-282002, Uttar Pradesh.

E-mail: ayush_kumar_singh@yahoo.co.in

DOI: $10.14260 /$ jemds $/ 2016 / 1697$
$\mathrm{K}$-wire fixation for both radius and supracondylar humerus if the fracture is displaced (Gartland type II and Type III). ${ }^{8,9,10,11}$

We have reported 10 cases with ipsilateral supracondylar humerus fracture with distal radius fracture over a period of 2 years between April 2013 and March 2015 treated at Grant Government Medical College and J. J. Hospital, Mumbai.

\section{Patients and Method}

Between April 2014 and March 2016, we came across 10 cases with ipsilateral supracondylar humerus and distal radius fracture, all between age group of 5-12 years. All of the patients presented within 24 hours of injury. One patient had grade 2 open (Gustilo-Anderson classification) Supracondylar humerus fracture with $2 \mathrm{~cm}$ lacerated wound over lateral aspect of distal humerus. The same patient had a $1 \mathrm{~cm}$ puncture wound over the volar aspect of distal radius with wrist drop. Ultrasound examination did not show any nerve discontinuity. Of the ten patients, seven had history of fall on outstretched hand, two had history of road traffic accident (hit by two wheeler) and one with grade 2 open fracture had history of fall from tree. No comorbidities were found in all these patients, and all patients were operated in emergency department within 6 hours of arrival at hospital. We used closed reduction and K-wire fixation for supracondylar humerus fracture from lateral side. Medial wire was used only if two lateral pins were insufficient in providing stability at fracture site. Closed reduction was achieved by milking manoeuvre as described by Peter, Scott and Stevens. ${ }^{8}$ Only the patient with the open fracture underwent thorough wound wash and debridement and open reduction with $\mathrm{K}$-wire fixation. All the displaced distal radius fractures underwent closed reduction and K-wire fixation using 2 crossed wires. $2,3,9$ All procedures were done in accordance with ethical 
standards. Postoperatively, the limb was immobilised in above elbow cast with forearm in supination except in the open fracture where elbow spanning external fixator was applied. Only one dose of broad spectrum intravenous antibiotic (Cephalosporin) calculated on weight basis was given in the patients having the closed fractures requiring pinning. The child with the open fracture received intravenous antibiotic consisting of Gram positive and Gram negative coverage (Cephalosporin and aminoglycoside) for two days postoperatively with daily dressing to look for any sign of infection. Immediate post-operative $\mathrm{x}$-rays were taken and then repeat x-rays at 4 weeks , 6 weeks and 8 weeks and 12 weeks and then once in 6 months. We have at least a 6-month follow-up of all patients. All patients were assessed by Flynn's criteria modified by Templeton and Graham at 6-month follow-up. ${ }^{10,11}$

\section{RESULTS}

Of 10 patients, nine patients had excellent functional outcome at 6 months with one having fair outcome due to presence of wrist drop which has partially recovered. The same patient had superficial pin tract infection which healed after removal of pins at 5 weeks and antibiotic coverage. The other nine patients had no pin tract infection. All fractures showed signs of union by 6 weeks as seen on follow-up x-ray following which the wires of both humerus and radius were removed. No fracture went into mal-union or non-union. No incidence of loss of reduction was seen. No vascular injury was seen in any of the cases.

\section{DISCUSSION}

The reported incidence of ipsilateral supracondylar humerus fracture with forearm fracture varies from $2 \%$ to $13 \%$. Among them, fracture of distal radius/ulna are less common. In our cases, all supracondylar humerus fracture were of extension type with the displaced fractures having a posteromedial displacement (Gartland type 3). All radius fractures were of extension type with dorsal displacement and dorsal angulation. Our study recommends a screening x-ray of the forearm and wrist in all patients with supracondylar humerus fractures to rule out any associated forearm or wrist injury. We recommend closed reduction and K-wire fixation for both supracondylar humerus (Type III) and distal radius fracture. We also recommend conservative management of nerve injury which usually recovers on observation and surgical exploration is required only if ultrasound examination shows any discontinuity in nerve. We had only one fair result at 6 month follow-up due to recovering radial nerve palsy restricting active wrist dorsiflexion up to 45 degrees. In all our patients, the supracondylar humerus fracture was operated first followed by distal radius fracture as recommended by Templeton and Graham. ${ }^{11}$

\begin{tabular}{|c|c|c|c|c|}
\hline & $\begin{array}{c}\text { Loss of Elbow Flexion/ } \\
\text { Extension }\end{array}$ & $\begin{array}{c}\text { Loss of Forearm Pronation/ } \\
\text { Supination }\end{array}$ & $\begin{array}{c}\text { Loss of Wrist Flexion/ } \\
\text { Extension }\end{array}$ & $\begin{array}{c}\text { Change in Carrying } \\
\text { Angle }\end{array}$ \\
\hline Excellent & $0-5$ & $0-15$ & $0-15$ & $0-5$ \\
\hline Good & $6-10$ & $16-30$ & $16-30$ & $6-10$ \\
\hline Fair & $11-15$ & $31-45$ & $31-45$ & $11-15$ \\
\hline Poor & $>15$ & $>45$ & $>45$ & $>15$ \\
\hline \multicolumn{2}{r}{} \\
\hline
\end{tabular}

\$Function is compared with uninjured limb
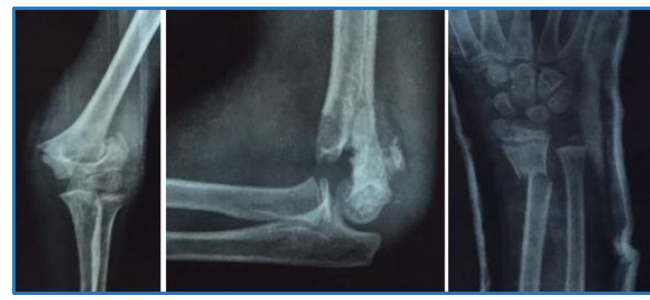

Preoperative X-ray of one Patient

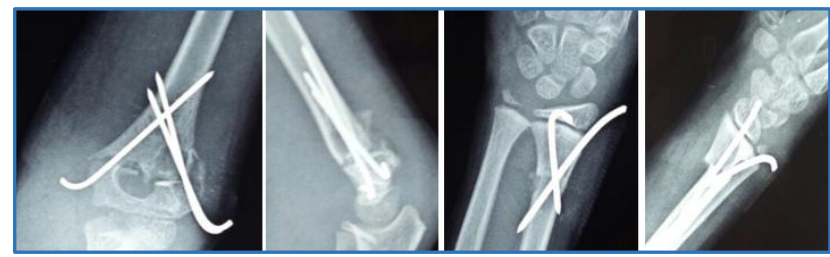

Immediate Post-operative X-ray

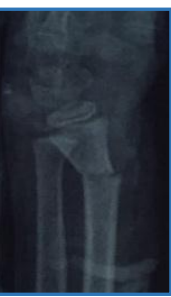

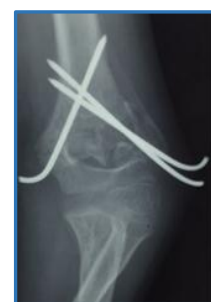
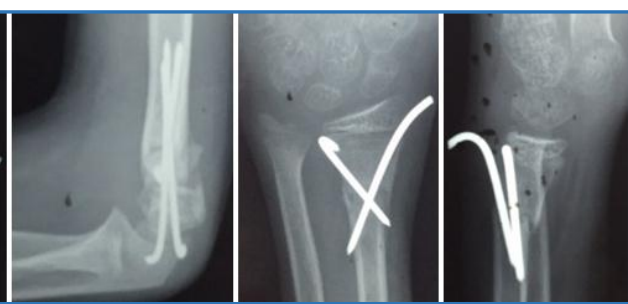

Post-operative 6 Weeks

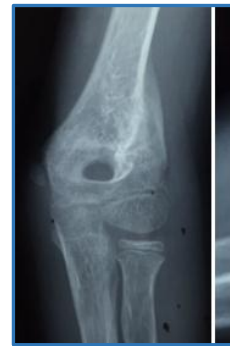

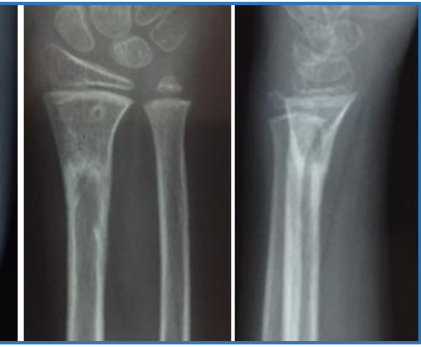

Post- operative 3 Months 


\begin{tabular}{|c|c|c|c|c|c|c|c|}
\hline $\begin{array}{l}\text { Sr. } \\
\text { No. }\end{array}$ & $\begin{array}{l}\text { Age } \\
\text { (Yrs.) }\end{array}$ & Sex & Injury & Classification & $\begin{array}{c}\text { Neuro- } \\
\text { Vascular } \\
\text { Status }\end{array}$ & $\begin{array}{c}\text { Union } \\
\text { Time (Week) }\end{array}$ & $\begin{array}{c}\text { \$Functional } \\
\text { Outcome } \\
\text { at } 6 \mathrm{Weeks}\end{array}$ \\
\hline 1 & 7 & M & Fall while Playing & Gartland Type II & Nil & 6 & Excellent \\
\hline 2 & 8 & $\mathrm{M}$ & Fall while Playing & Gartland Type I & Nil & 6 & Excellent \\
\hline 3 & 8 & $\mathrm{~F}$ & Road Traffic Accident & Gartland Type III & Nil & 6 & Excellent \\
\hline 4 & 9 & $\mathrm{M}$ & Fall from Stairs & Gartland Type III & Nil & 6 & Excellent \\
\hline 5 & 12 & $\mathrm{~F}$ & Fall from Tree & $\begin{array}{c}\text { Grade } 2 \text { Open/ } \\
\text { Gartland Type III }\end{array}$ & Wrist Drop & 6 & Fair \\
\hline 6 & 9 & $\mathrm{M}$ & Road Traffic Accident & Gartland Type III & Nil & 6 & Excellent \\
\hline 7 & 8 & $\mathrm{M}$ & Fall while Playing & Gartland Type I & Nil & 6 & Excellent \\
\hline 8 & 7 & M & $\begin{array}{c}\text { Fall on Outstretched } \\
\text { Hand }\end{array}$ & Gartland Type III & Nil & 6 & Excellent \\
\hline 9 & 10 & M & $\begin{array}{c}\text { Fall on Outstretched } \\
\text { Hand }\end{array}$ & Gartland Type III & Nil & 6 & Excellent \\
\hline 10 & 6 & M & $\begin{array}{c}\text { Fall on Outstretched } \\
\text { Hand }\end{array}$ & Gartland Type I & Nil & 6 & Excellent \\
\hline \multicolumn{8}{|c|}{ Functional Outcome after 6 Weeks of Operative Management } \\
\hline
\end{tabular}

\$: Flynn et al Criteria

\section{RESULTS}

Of 10 patients, nine patients had excellent functional outcome at 6 months with one having fair outcome due to presence of wrist drop which has partially recovered. The same patient had superficial pin tract infection which healed after removal of pins at 5 weeks and antibiotic coverage. The other nine patients had no pin tract infection. All fractures showed signs of union by 6 weeks as seen on follow-up x-ray following which the wires of both humerus and radius were removed. No fracture went into mal-union or non-union. No incidence of loss of reduction was seen. No vascular injury was seen in any of the cases.

\section{DISCUSSION}

The reported incidence of ipsilateral supracondylar humerus fracture with forearm fracture varies from $2 \%$ to $13 \%$. Among them, fracture of distal radius/ulna are less common. In our cases, all supracondylar humerus fractures were of extension type with the displaced fractures having a posteromedial displacement (Gartland type 3). All radius fractures were of extension type with dorsal displacement and dorsal angulation. Our study recommends a screening x-ray of the forearm and wrist in all patients with supracondylar humerus fractures to rule out any associated forearm or wrist injury. We recommend closed reduction and K-wire fixation for both supracondylar humerus (Type III) and distal radius fracture. We also recommend conservative management of nerve injury which usually recovers on observation and surgical exploration is required only if ultrasound examination shows any discontinuity in nerve. We had only one fair result at 6 month follow-up due to recovering radial nerve palsy restricting active wrist dorsiflexion up to 45 degrees. In all our patients, the supracondylar humerus fracture was operated first followed by distal radius fracture as recommended by Templeton and Graham. ${ }^{11}$

\section{CONCLUSION}

This study recommends a screening $\mathrm{x}$-ray of the forearm and wrist in all patients with supracondylar humerus fractures to rule out any associated forearm or wrist injury. We also recommend closed reduction and K-wire fixation of the displaced supracondylar humerus as well as distal radius fracture. Any nerve palsy if present should be conservatively managed and should be observed for at least 6 weeks before considering surgical exploration.

\section{Acknowledgment}

I would like to acknowledge all my faculty, all residents and $\mathrm{x}$ ray technicians for their valuable contribution.

\section{REFERENCES}

1. Dhoju D, Shrestha D, Parajuli N, et al. Ipsilateral supracondylar fracture and forearm bone injury in children: a retrospective review of thirty one cases. Kathmandu Univ Med J (KUMJ) 2011;9(34):11-6.

2. Siemers F, Obertacke U, Fernandez ED, et al. Combination of ipsilateral supracondylar humeral-and forearm fractures in children. Zentralbl Chir 2002;127(3):212-7.

3. Tabak AY, Celebi L, Muratli HH, et al. Closed reduction and percutaneous fixation of supracondylar fracture of the humerus and ipsilateral fracture of the forearm in children. J Bone Joint Surg Br 2003;85(8):1169-72.

4. Powell RS, Bowe JA. Ipsilateral supracondylar humerus fracture and Monteggia lesion: a case report. J Orthop Trauma 2002;16(10):737-40.

5. McLauchlan GJ, Walker CR, Cowan B, et al. Extension of the elbow and supracondylar fractures in children. J Bone Joint Surg Br 1999;81(3):402-5.

6. Rouhani AR, Navali AM, Sadegpoor AR, et al. Monteggia lesion and ipsilateral humeral supracondylar and distal radial fractures in a young girl. Saudi Med J 2007;28(7):1127-8.

7. Cobanoglu M, Şavk ŞO, Cullu E, et al. Ipsilateral supracondylar humerus fracture and Monteggia lesion with a 5-year follow-up: a rare injury in a young girl. BMJ Case Rep 2015;2015.

8. Peters CL, Scott SM, Stevens PM. Closed reduction and percutaneous pinning of displaced supracondylar fractures in children: description of a new closed reduction technique for fractures with brachialis muscle entrapment. J Orthop Trauma 1995;9(5):430-4.

9. Biyani A, Gupta SP, Sharma JC. Ipsilateral supracondylar fracture of humerus and forearm bones in children. Injury 1989;20(4):203-7. 
10. Flynn JC, Matthews JG, Benoit RL. Blind pinning of displaced supracondylar fractures of the humerus in children: sixteen years' experience with long-term followup. J Bone Joint Surg Am 1974;56(2):263-72.
11. Templeton PA, Graham HK. The 'floating elbow' in children. Simultaneous supracondylar fractures of the humerus and of the forearm in the same upper limb. J Bone Joint Surg Br 1995;77(5):791-6. 